\title{
Parotid Gland Metastasis of Breast Cancer: Case Report and Review of the Literature
}

\author{
Katsutoshi Ando ${ }^{a}$ Norio Masumoto ${ }^{a}$ Masaaki Sakamoto ${ }^{a}$ Kou Teraoka ${ }^{a}$ Takako Suzuki $^{\mathrm{a}}$ \\ Terumasa Kurihara $^{a}$ Satoko Abe ${ }^{a}$ Mitsuhiro Tozaki ${ }^{a}$ Eisuke Fukuma ${ }^{a}$ Kazuei Hoshi ${ }^{b}$
}

${ }^{a}$ Breast Center,

${ }^{b}$ Department of Pathology, Kameda Mecical Center, Kamogawa, Chiba, Japan

\section{Keywords}

Parotid gland metastasis - Breast cancer - Trastuzumab

\section{Summary}

Background: Parotid gland metastasis in breast cancer is extremely rare, and only 14 cases have been reported between 1982 and 2010. Case Report: A 67-year-old female patient was diagnosed with invasive lobular carcinoma of the left breast. Although clinical staging was T1N3M1 (stage IV), the tumor experienced a complete response to chemotherapy. We therefore performed a mastectomy followed by radiotherapy, and continued administration of trastuzumab. However, 11 months later, the patient complained of a swelling in the left parotid gland. Histology following a partial parotidectomy revealed a parotid gland metastasis from the breast. Conclusion: Treatment with capecitabine in addition to trastuzumab, which is one of the strategies applied in HER2-positive breast cancer, was effective in our patient. Analysis of the 14 cases of parotid gland metastasis from the breast reported between 1982 and 2010 revealed that the metastasis may occur not by direct lymphatic but by hematogenous spread.

\section{Introduction}

In the head and neck tumors, salivary gland tumors, especially metastatic, are rare clinical events. Metastatic parotid gland involvement accounts for approximately $9-14 \%$ of all parotid tumors [1]. Metastasis to the parotid gland from breast cancer

\author{
Schlüsselwörter \\ Parotismetastase - Mammakarzinom - Trastuzumab
}

\section{Zusammenfassung}

Hintergrund: Aus Mammakarzinomen entstehende Parotismetastasen sind extrem selten, und zwischen 1982 und 2010 wurden nur 14 solche Fälle berichtet. Fallbericht: Bei einer 67-jährigen Patientin wurde ein invasiv lobuläres Karzinom der linken Brust diagnostiziert. Trotz des fortgeschrittenen klinischen Stadiums (T1N3M1, Stadium IV) konnte ein komplettes Ansprechen auf die Chemotherapie erzielt werden. Aus diesem Grund wurde eine Mastektomie gefolgt von Radiotherapie durchgeführt und die Trastuzumab-Therapie fortgesetzt. 11 Monate später bemerkte die Patientin jedoch einen Knoten in der Parotisdrüse. Die histologische Untersuchung im Anschluss an eine partielle Parotidektomie ergab eine Parotismetastase des Mammakarzinoms. Schlussfolgerung: Die Behandlung mit Capecitabine zusätzlich zu Trastuzumab, was eine beim HER2-positiven Mammakarzinom angewandte Strategie ist, war bei unserer Patientin effektiv. Die Analyse der 14 Fallberichte zu Parotismetastasen von Mammakarzinomen (1982-2010) ergab, dass es sich möglicherweise um eine hämatogene statt einer direkt lymphogenen Metastasierung handelt.

is extremely rare, and to our knowledge only 14 cases have been reported between 1982 and 2010 [2-10]. We report a case of invasive lobular carcinoma of the breast which spread to the parotid gland, and we summarize the 14 cases that have been reported.

\section{KARGER \\ Fax +497614520714 \\ Information@Karger.de}

www.karger.com
(C) 2011 S. Karger GmbH, Freiburg

$1661-3791 / 11 / 0066-0471 \$ 38.00 / 0$

Accessible online at:

www.karger.com/brc
Katsutoshi Ando, MD

Breast Center

929 Higashicho, Kamogaw

Chiba, 296-8602, Japan

Tel. +81 4709-22211, Fax -91198

andokatutoshi@yahoo.co.jp 


\section{Case Report}

A 67-year-old female patient presented to our institution with a left-sided breast lump and swelling in the left axillary lymph nodes in September 2007. We performed a biopsy, and histology showed a Bloom and Richardson grade 3 invasive lobular carcinoma. Immunohistological study was negative for estrogen and progesterone receptors, and positive (score 3) for human epidermal growth factor receptor 2 (HER2). A routine metastatic workup revealed metastasis to the bilateral cervical and supraclavicular lymph nodes, and the clinical stage was diagnosed as cT1N3M1(stage IV). The patient received 6 cycles of FEC-60 (fluorouracil $500 \mathrm{mg} / \mathrm{m}^{2}$, epirubicin $60 \mathrm{mg} / \mathrm{m}^{2}$, cyclophosphamide $500 \mathrm{mg} / \mathrm{m}^{2}$ ) followed by weekly paclitaxel $80 \mathrm{mg} / \mathrm{m}^{2}$ and trastuzumab. Chemotherapy resulted in a clinical complete response (revealed by positron emission tomography (PET)- computed tomography (CT) scan), and a left mastectomy with axillary clearance surgery was performed, followed by radiotherapy (45 Gy) to the bilateral neck, supraclavicular space, left axilla, and precordium. Moreover, we continued the administration of weekly trastuzumab because the tumor in the breast responded favorably to this drug resulting in a histological grade $2 \mathrm{~b}$.

In May 2009 (11 months after the operation), the patient presented to the Otolaryngology Department with a swelling in her left parotid gland, and a PET-CT scan revealed accumulation of standardized uptake value (SUV) 9.8 in that region (fig. 1). A primary parotid tumor was suspected, and a partial parotidectomy performed. Histology showed a poorly differentiated HER2-positive adenocarcinoma (fig. 2), resulting in the diagnosis of parotid gland metastasis from the breast. Capecitabine 1,650 mg/ $\mathrm{m}^{2} /$ day was started in addition to trastuzumab. Although a dose reduction of capecitabine was needed due to a grade 2 hand-foot syndrome, the size of the tumor in the parotid gland was reduced and the abnormal accumulation had improved on PET-CT in November 2009 (4 months after addition of capecitabine).

\section{Discussion}

Invasive ductal carcinoma is the most invasive histological pattern of breast cancer. Distant spread through the lymphatic route occurs to the mediastinal and supraclavicular lymph nodes. Also hematogenous spread occurs and leads to metastasis to lung, liver, bone, adrenals, and brain [10]. How-

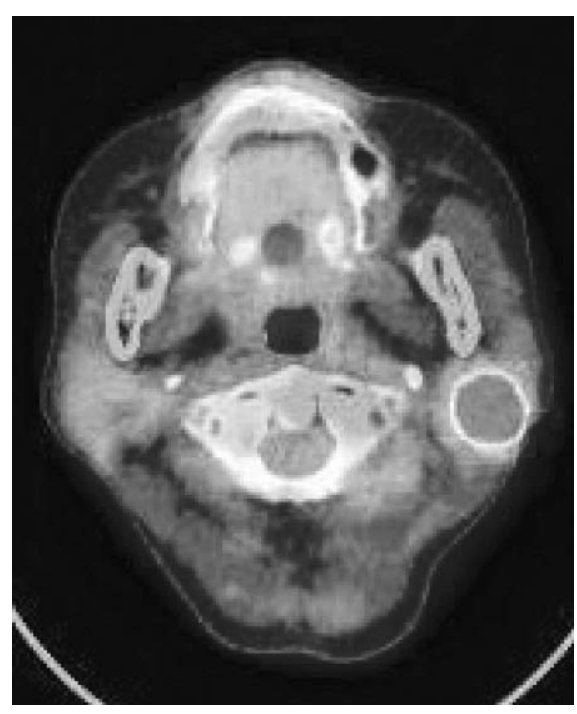

Fig.1. PET-CT scan revealed accumulation of SUV 9.8 in the left parotid gland. ever, metastasis to the parotid gland is a very rare clinical event for breast cancer. In a review of autopsy studies which included 167 cases of breast cancer, only 1 case of metastasis to the parotid gland was detected [11]. Also, a search of the MEDLINE database (1982-2010) revealed merely 14 cases (table 1) [2-10]. One reason for the rarity of this event is the anatomical location. Metastasis to the parotid gland usually arises from primaries in the head and neck. The parotid gland is divided into paraglandular lymph nodes, intraglandular lympatics, and parenchyma. The paraglandular and intraglandular lymphatics are common sites for metastasis from squamous cell carcinoma and melanoma of the scalp, ear, and the forehead by direct lymphatic drainage. On the other hand, parenchymal metastasis is considered to occur via hematogenous rather than lymphatic spread $[12,13]$. However, few reports document which area in the parotid gland is affected by metastasis, and the metastatic process remains to be elucidated. To our knowledge, 11 of the 14 patients had left parotid gland metastasis ( 5 primary breast carcinomas in the left and 5 in the right breast; 1 case unknown), and 3 patients had metastasis to the right parotid gland (1 primary in the left and 2 in the right breast). Since $5(45.5 \%)$ of the 11 patients with left parotid involvement had a primary carcinoma in the right breast, it is possible that the spread occurred via hematogenous as opposed to direct lymphatic metastasis.

For the treatment of this metastasis, parotidectomy, radiation, chemotherapy, and hormone therapy were performed. Regardless of the metastatic pathway, generalized treatment such as chemo- and hormone therapy is needed. Because immunohistochemical analysis in our case had revealed the tumor to be negative for estrogen and progesterone receptors and positive for HER2, we continued to administer trastuzumab postoperatively. Trastuzumab combined with chemotherapy drugs such as paclitaxel improves outcomes among women with surgically removed HER2-positive breast cancer [14]. It also improves disease-free survival if continued after



Fig. 2. Photomicrograph of a section through the parotid tumor revealing a metastatic invasive lobular carcinoma of the breast $(H \& E \times 400)$. 
Table 1. Case reports of parotid gland metastasis of breast cancer

\begin{tabular}{|c|c|c|c|c|c|c|c|c|}
\hline $\mathrm{n}$ & Author, year [ref.] & $\begin{array}{l}\text { Age, } \\
\text { years }\end{array}$ & Pathology & $\begin{array}{l}\text { Location } \\
\text { (breast) }\end{array}$ & $\begin{array}{l}\text { Location } \\
(\mathrm{PG})\end{array}$ & Symptom & Form of onset & Treatment \\
\hline 1 & Wiesel et al., 1982 [2] & 62 & ILC & left & left & swelling & recurrence & RT \\
\hline 2 & Wiesel et al., 1982 [2] & 61 & IDC & left & left & swelling & recurrence & parotidectomy, CT \\
\hline 3 & Wiesel et al., 1982 [2] & 74 & - & left & left & FN palsy & recurrence & radiotherapy, CT \\
\hline 4 & Bissett et al., 1989 [3] & 41 & IDC & right & left & FN palsy & recurrence & RT \\
\hline 5 & Bissett et al., 1989 [3] & 65 & - & right & left & swelling & recurrence & RT, CT \\
\hline 6 & Calvo et al., 1995 [4] & 57 & IDC & right & left & pain & recurrence & parotidectomy \\
\hline 7 & Joyce et al., 2000 [5] & 71 & IDC & right & right & FN palsy & recurrence & parotidectomy \\
\hline 8 & Szymanski et al., 2002 [6] & 66 & IDC & right & left & FN palsy & recurrence & parotidectomy \\
\hline 9 & Szymanski et al., 2002 [6] & 58 & IDC & right & right & swelling & metastasis & parotidectomy, RT, CT \\
\hline 10 & Zhang et al., 2003 [7] & 40 & phyl & left & right & swelling & metastasis & - \\
\hline 11 & Perez et al., 2007 [8] & 61 & IDC & - & left & mass in $\mathrm{PG}$ & recurrence & parotidectomy, RT, CT \\
\hline 12 & Laforga et al., 2009 [9] & 52 & IDC & left & left & mass in $\mathrm{PG}$ & recurrence & parotidectomy, RT, CT \\
\hline 13 & Dangore et al., 2009 [10] & 42 & IDC & right & left & swelling & metastasis & parotidectomy, RT, CT \\
\hline 14 & Ando K 2010 [unpublished] & 65 & ILC & left & left & swelling & recurrence & parotidectomy, CT \\
\hline
\end{tabular}

ILC = Invasive lobular carcinoma; IDC = invasive ductal carcinoma; phyl = malignant phyllodes tumor; FN = facial nerve; $\mathrm{PG}=$ parotid gland; $\mathrm{RT}=$ radiotherapy CT $=$ chemotherapy.

adjuvant chemotherapy [15]. However, the effect of postoperative adjuvant chemotherapy in stage IV breast cancer patients is controversial.

In spite of various treatments, in this case, the patient experienced a relapse 11 months after operation. At that time, there were some treatment options such as to continue or discontinue trastuzumab (change to lapatinib) and start or not start chemotherapy. Lapatinib, a tyrosine kinase inhibitor of HER2 and epidermal growth factor receptor, is an active combination with capecitabine in women with HER2-positive metastatic breast cancer that has progressed after trastuzumab-based therapy [16]. We started capecitabine in addition to trastuzumab, which is one of the strategies applied in
HER2-positive breast cancer, and this approach proved effective.

The case presented here had an unusual clinical course. Oncologists should keep in mind that the clinical course or imaging findings are not always in line with common patterns. Rare presentations such as in our case are possible, and we should always strive for a histopathologic diagnosis.

\section{Disclosure Statement}

K.A. desclares that he has no financial or personal relationships with other people or organizations that could inappropriately influence his actions. The other authors did not provide a conflict of interest statement.

\section{References}

1 Batsakis JG: Pathology consultation: parotid gland and its lymph nodes as metastatic sites. Ann Otol Rhinol Laryngol 1983;92:209-210.

2 Wiesel JM, Weshler Z, Sherman Y, Gay I: Parotid gland metastatic carcinoma of breast origin. J Surg Oncol 1982;20:227-230.

3 Bissett D, Bessell EM, Bradley PJ, Morgan DAL, Mckenzie CG: Parotid gland from metastasis of the breast. Clin Radiol 1989;40:309-310.

4 Calvo Boizas E, Rodriguez Gutierrez A, Munoz Herrera A, Soria Carreras P: Metastasis of breast carcinoma in parotid. A case report and review of the literature. Acta Otorrinolaring Esp 1995;46:391-393.

5 Joyce MR, Awad ZT, Saleem T, Salmo EN, Gormley M, Given HF: The parotid gland: an unusual site of metastasis from carcinoma of breast. Ir J Med Sci 2000;169:230

6 Szymanski M, Siwiec H, Olszanski W, Golabek W: Parotid metastases from breast cancer. Wiad Lek 2002;55:494-497.

7 Zhang JZ, Gu M: Malignant phyllodes tumor of the breast metastatic to the parotid gland diagnosed by fine needle aspiration biopsy. A case report. Acta Cytol 2003;47:253-258.
8 Perez-Fidalgo JA, Chirivella I, Laforga J, Colio JM, Blanes MD, Baydal R, Rosello S, De-la-Morena E, Lluch A: Parotid gland metastasis of a breast cancer. Clin Transl Oncol 2007;9:264-265.

9 Laforga JB, Gasent JM: Mammary invasive duct carcinoma metastatic to parotid gland: report of a case diagnosed by fine-needle aspiration. Diagn Cytopathol 2009;37:154-158.

10 Dangore-Khasbage SB, Degwekar SS, Bhowate RR, Bhake A: Metastatic involvement of parotid from carcinoma of the breast: a case report. Oral Maxillofac Surg 2009;13:49-53.

11 Abrams HL, Spiro R, Goldstein N: Metastases in carcinoma. Cancer 1950;3:74-85.

12 Graham JW: Metastatic cancer in the parotid lymph nodes. Med J Aust 1965;2:8-12.

13 Coulthard SW: Metastatic cancer in the parotid gland. Otolaryngol Clin North Am 1977;10:437442

14 Romond EH, Perez EA, Bryant J, Suman VJ, Geyer CE, Davidson NE, Tan-Chiu E, Martino S, Palk S, Kaufman PA, Swain SM, Pisansky TM, Fehrenbacher L, Kutteh LA, Vogel VG, Visscher DW, Yothers G, Jenkins RB, Brown AM, Dakhil SR, Mamounas EP, Lingle WL,
Klein PM, Ingle JN, Wolmark N: Trastuzumab plus adjuvant chemotherapy for operable HER2-positive breast cancer. N Engl J Med 2005;353:16731684

5 Piccart-Gebhart MJ, Procter M, Leyland-Jones B, Goldhirsch A, Untch M, Smith I, Gianni L, Baselga J, Bell R, Jackisch C, Cameron D, Dowsett M, Barrios $\mathrm{CH}$, Steger G, Huang CS, Andersson M, Inbar M, Lichinister M, Lang I, Nitz U, Iwata $\mathrm{H}$, Thomssen C, Lohrisch C, Suter TM, Ruschoff J, Suto T, Greatorex V, Ward C, Straehle C, McFadden E, Dolci MS, Gelber RD; Herceptin Adjuvant Trial Study Team: Trastuzumab after adjuvant chemotherapy in HER2-positive breast cancer. N Engl J Med 2005;353:1659-1672.

16 Geyer CE, Forster J, Lindquist D, Chan S, Romieu CG, Pienkowski T, Jagiello-Gruszfeld A, Crown J, Chan A, Kaufman B, Skarlos D, Campone M, Davidson N, Berger M, Oliva C, Rubin SD, Stein S, Cameron D: Lapatinib plus capecitabine for HER2-positive advanced breast cancer. N Engl J Med 2006:355:2733-2743. 